PREPARED FOR THE U.S. DEPARTMENT OF ENERGY, UNDER CONTRACT DE-AC02-76CH03073

PPPL-3559

PPPL-3559

UC-70

A Lower Hybrid Current Drive System for Alcator C-Mod

by

S. Bernabei, J.C. Hosea, D. Loesser, J. Rushinski, J.R. Wilson, P. Bonoli, M. Grimes, R. Parker, M. Porkolab, D. Terry, and P. Woskov

May 2001

NM|

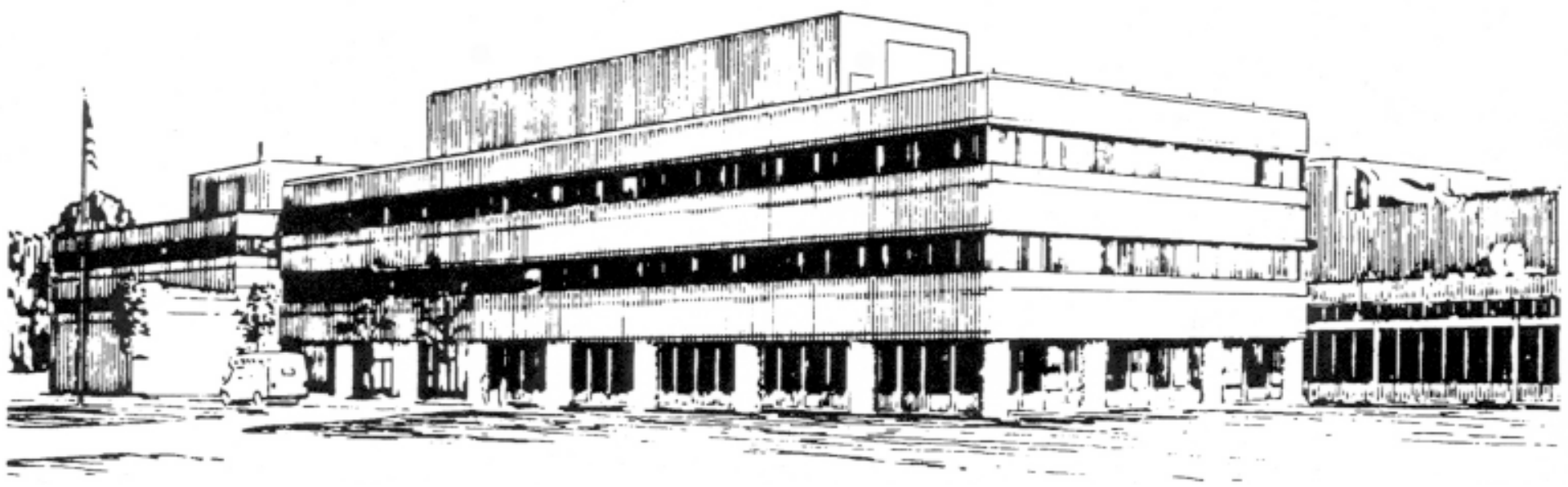

PRINCETON PLASMA PHYSICS LABORATORY PRINCETON UNIVERSITY, PRINCETON, NEW JERSEY 


\section{PPPL Reports Disclaimer}

This report was prepared as an account of work sponsored by an agency of the United States Government. Neither the United States Government nor any agency thereof, nor any of their employees, makes any warranty, express or implied, or assumes any legal liability or responsibility for the accuracy, completeness, or usefulness of any information, apparatus, product, or process disclosed, or represents that its use would not infringe privately owned rights. Reference herein to any specific commercial product, process, or service by trade name, trademark, manufacturer, or otherwise, does not necessarily constitute or imply its endorsement, recommendation, or favoring by the United States Government or any agency thereof. The views and opinions of authors expressed herein do not necessarily state or reflect those of the United States Government or any agency thereof.

\section{Availability}

This report is posted on the U.S. Department of Energy's Princeton Plasma Physics Laboratory Publications and Reports web site in Calendar Year 2001. The home page for PPPL Reports and Publications is: http://www.pppl.gov/pub_report/

DOE and DOE Contractors can obtain copies of this report from:

U.S. Department of Energy

Office of Scientific and Technical Information

DOE Technical Information Services (DTIS)

P.O. Box 62

Oak Ridge, TN 37831

Telephone: (865) 576-8401

Fax: (865) 576-5728

Email: reports@adonis.osti.gov

This report is available to the general public from:

National Technical Information Service

U.S. Department of Commerce

5285 Port Royal Road

Springfield, VA 22161

Telephone: 1-800-553-6847 or

(703) 605-6000

Fax: (703) 321-8547

Internet: http://www.ntis.gov/ordering.htm 


\title{
A Lower Hybrid Current Drive System for Alcator C-Mod.
}

\author{
S. Bernabei, J.C. Hosea, D. Loesser, J. Rushinski, J. R. Wilson, \\ PPPL, Princeton University, \\ P. Bonoli, M. Grimes, R. Parker, M. Porkolab, D. Terry, P. Woskov, \\ PSFC, MIT.
}

\begin{abstract}
A Lower Hybrid Current Drive system is being constructed jointly by PSFC and PPPL for installation on the Alcator C-Mod tokamak, with the primary goal of driving plasma current in the outer region of the plasma. The LH system consists of $3 \mathrm{MW}$ power at $4.6 \mathrm{GHz}$ with a maximum pulse length of 5 seconds. 12 Klystrons will feed an array of 4-vertical and 24horizontal waveguides mounted in one equatorial port. The coupler will incorporate some compact characteristics of the multijunction power splitting while retaining full control of the toroidal phase. In addition a dynamic phase control system will allow feedback stabilization of MHD modes. The desire to avoid possible waveguide breakdown and the need for compactness have resulted in some innovative technical solution, which will be presented.
\end{abstract}

ARIES studies show the remarkable improvement in the attractiveness of a tokamak reactor that results from AT physics operation: ARIES-AT requires LHCD for off-axis seed current [1]. In Alcator C-Mod, the LHCD experiment is designed to aid in the achievement of AT regimes with high bootstrap fraction $(\sim 70 \%)$, high $\beta_{\mathrm{n}}(\geq 3)$ and high confinement $(\mathrm{H} \sim 2-3)$ under quasi-steady-state conditions. LHCD current in the range of $150-270 \mathrm{kA}$ is expected to be driven at $0.6<\mathrm{r} / \mathrm{a}<0.8$ : this, in conjunction with the heating obtained by $8 \mathrm{MW}$ of ICRF power, will allow the development and study of Advanced Tokamak Regimes under quasi-steady-state conditions [2]. The high electron temperature predicted with $5 \mathrm{MW}$ of ICRF $\left(\mathrm{T}_{\mathrm{eo}} \sim 5-7 \mathrm{keV}\right.$ ) insures first-pass damping of the $\mathrm{LH}$ waves, and therefore very good localization of the damping [3].

The RF power generation will utilize 12 high-power C-band klystrons. The klystrons, CPI (formally Varian) model VKC-7849, were originally purchased over 20 years ago for the Alcator-C Lower Hybrid experiment. The klystrons are cathode switched (no control connection) and are rated at an output of $250 \mathrm{~kW} \mathrm{CW}$ at $4.6 \mathrm{GHz}$. The transmitters are arranged in carts with 4 klystrons each. For system flexibility, each cart is controlled semi-independently of the others with its own fast-off Transmitter Protection System (TPS) and PLC controller. Critical protection, control, and status lines are shared for coordination.

The klystrons are powered by a single high-voltage power supply/modulator which was specified and procured custom for this application from Thomcast AG of Switzerland. The HVPS is based on Pulse Step Modulation (PSM) technology using 68 individual solid-state modules. The HVPS also acts as the modulator since the klystrons conduct with the application of high voltage. The supply is rated for an output of $50 \mathrm{kV}$ at $208 \mathrm{~A}$ for a 5 second maximum pulse width. The supply will be housed in a custom outdoor two-story container with the high voltage routed to the transmitter carts via a special high-voltage tri-axial cable. The supply has its own fault sensing and protection system and is linked via fiber-optic cable to the TPS and the Allen-Bradley" PLC controller associated with each klystron cart. 
The output $\mathrm{RF}$ from each klystron is routed to the coupler by $\mathrm{TE}_{10}$ rectangular waveguide (WR 187). The initial plan is to pressurize the waveguide with 2-bar nitrogen or dry air with a backup plan of using $\mathrm{SF}_{6}$ if necessary. The klystrons are protected from reflected power by a 4-port ferrite circulator specified custom for this application and procured from Advanced Ferrite Technology of Germany. The circulator is rated to handle full reflection at full power over the entire 5 -second pulse width with a forward insertion loss of less than $0.2 \mathrm{~dB}$.

The coupler is protected from potentially damaging high VSWR or waveguide arcs by the Coupler Protection System (CPS). The CPS monitors a total of 60 forward and 156 reverse power sample points to generate 156 possible high VSWR fault conditions. The CPS is linked to the transmitter TPS by fiber optic links to provide fast shutoff of the input RF to the appropriate klystron in the event of a fault. A digital controller is used to provide

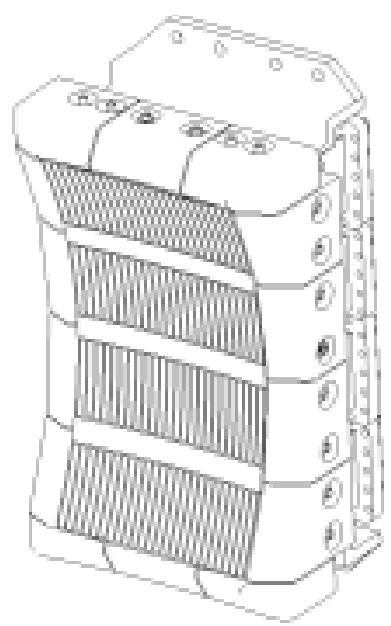

Fig. 1 Front coupler active phase and amplitude control of the twelve klystrons with a $1 \mathrm{~ms}$ response time. Fast solid-state I-Q vector modulators are used as the phase and amplitude control elements for the low-level microwave drive signals to the klystrons. Phase and amplitude feedback information is provided to the controller by twelve I-Q detectors.

The dimensions of the port and the power density achievable at this frequency dictate the configuration of the front coupler: it will consist of 4 rows of 24 waveguides each (Fig. 1). The dimension of each waveguide is $6 \times 0.55 \mathrm{~cm}^{2}$; for

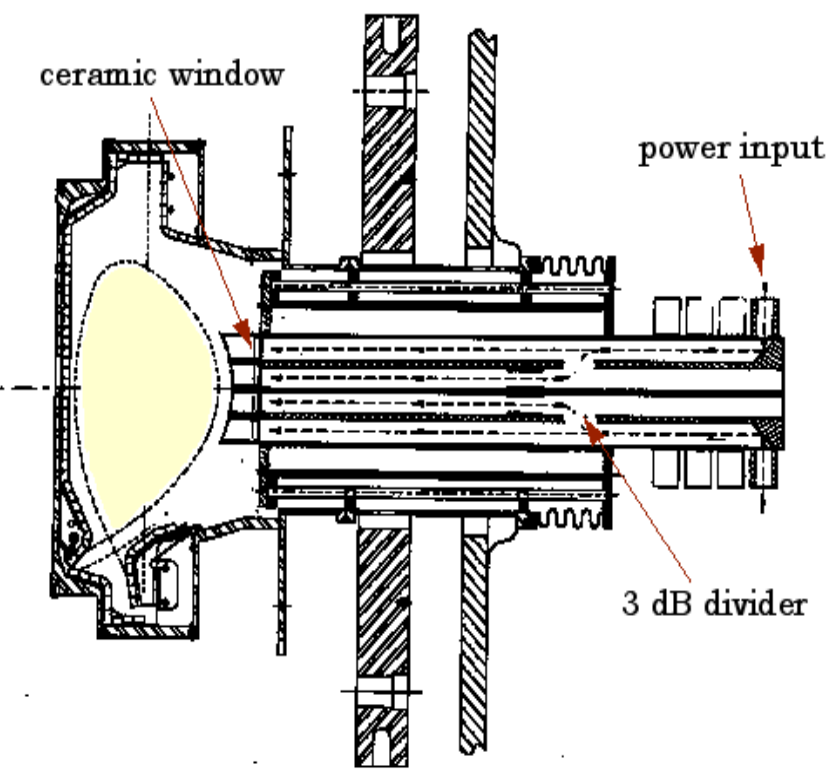

Fig. 2 Elevation view of the LH coupler $2 \mathrm{MW}$ source power the expected power density at the coupler mouth is $\leq 5 \mathrm{~kW} / \mathrm{cm}^{2}$, which is below the empirical limit for breakdown.

The design principles of the coupler have been maximum flexibility in the control of the $n_{\|}$ spectrum and maximum reliability, together with the desire of compactness because of the tight configuration of C-Mod.

The elevation view is shown in figure 2 . The construction of the 4 arrays of waveguides is obtained by 
milling the waveguide patterns on metal plates and by stacking and bolting them. Each Klystron feeds a total of 8 waveguides, two adjacent vertical columns. The stacked plates array includes a vertical $3 \mathrm{~dB}$ divider. A fixed phase shifter compensates for the difference in phase due to the splitter and to the different length of the channels, so that at the mouth vertically the phase is constant. The schematic in figure 3 shows how the phase across the arrays is fully controlled: a high power phase shifter adjusts the phase between the two adjacent columns to the desired value, while a low power phase shifter before each Klystron adjusts the phase between the modules of two waveguides. This second phase shifter is a ferrite device capable of changing the phase in microseconds: this allows the very high degree of $n_{\|}$spectrum control in real time needed for feedback stabilization of MHD modes.

Historically a weak point in terms of waveguide arcing in LH couplers have been

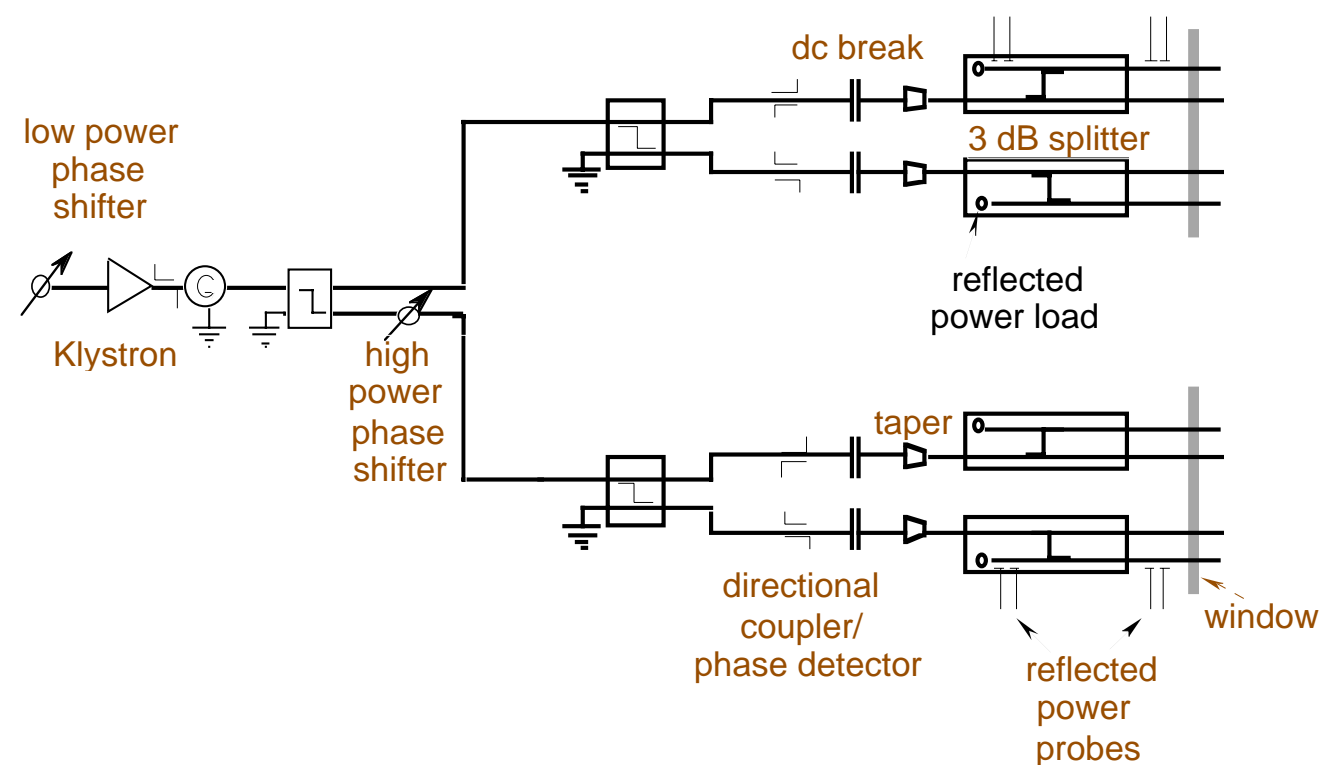

Fig.3 Schematic of the transmission line

the existence in vacuum of the layer where $\omega=\omega_{\text {ce }}$, which is somewhere near the magnetic field coil location. Other weak points have been the vacuum joints of the waveguide lines: we decided to eliminate both types of potential problems by incorporating the microwave vacuum window in the nose coupler. We already have achieved a high degree of reliability in brazing multiple alumina windows on a Titanium alloy frame [4], for C-Mod we plan to braze the 24 alumina breaks inside the 24 channels, each cut $10 \mathrm{~cm}$ deep in a Titanium alloy block via EDM-wire. Not only the electron cyclotron resonance layer will be in a pressurized area, but all the waveguide joint will be as well. Because Titanium absorbs Hydrogen gas, which could cause breakdown if it escapes from the wall, care will be taken to coat the waveguide channels with a metal, which has also a low secondary electron emission to minimize multipacting, such as Copper or Silver. The coupler nose will be protected by Boron-Nitride tiles (see figure 1). The radial position of the entire launcher can be adjusted in order to optimize coupling. 
In ideal conditions, the reflection on vertically placed waveguides will be in phase and the power will be directed toward the generator and dissipated in the circulator. In practice we should expect the density in front of the coupler to vary somewhat vertically, in part because of the geometry of the machine and in part due to the ponderomotive force applied by the LH waves. In this case some of the reflected power will be directed toward the "fourth arm" of the $3 \mathrm{~dB}$ divider (see figure 2). The obvious solution would be to insert a load in each channel to dissipate this reflected power; for most of the waveguides this could be possible, but depending on the particular phasing chosen, some waveguides will receive a very high percentage of the power, in some cases even close to $100 \%$ because of cross-coupling. It is very difficult to insert a load in the narrow space of the waveguides $(0.55 \mathrm{~cm}$ width). It would be also very cumbersome and expensive to transition to standard waveguide in order to have a full size load. There would be the possibility of leaving the "fourth arm" shorted, but in this case the reflection would alter the phase of the forward wave. Therefore we plan to unite all 24 loads of each array into one, by inserting dielectric pipes perpendicular to the stack plates and run water through them: this will achieve two things, absorb the reflected power and transport away the heat generated. It turns out that a single broad pipe, carrying enough water to absorb up to $\sim 20 \%$ of the total power causes unwanted reflections. Using models obtained from the HFSS $^{\text {TM }}$ simulator we found that the best configuration is to have $45 / 16$ " o. d. Teflon pipes appropriately placed. They will be mounted on a separate stack of plates, with a flange which allows the attachment to the rear of the coupler assembly. This way, different configurations and even a simple short can be tested.

$\mathrm{Rf}$ probes of the kind described in [5] inserted on the narrow sides of the top and bottom arrays will allow measurement of the power flow in each waveguide. In figure 2 , taper refers to the transition from standard WR187 waveguide to a reduced size: up to that point all the components are standard.

Aside from the movement for coupling optimization, the coupler assembly can be separated from the machine and rolled out either for inspection or for replacement of one of the front components, which are the one more likely to sustain damage. The rest are standard components and readily reachable.

\section{ACKNOWLEDGEMENTS}

*Work supported by US DOE Contract No. DE-AC02-76CH03073 and US DOE Cooperative Agreement DE-FC02-99ER54512

\section{REFERENCES}

[1] S. C. Jardin, C. E. Kessel, C. G. Bathke, D. A. Ehst, T. K. Mau, F. Najmabadi, T. W. Petrie, and the ARIES Team, Fusion Engineering and Design, 38, (1997) 27.

[2] P.T. Bonoli, M.Porkolab, J.J. Ramos, W.M. Nevins, C. Kessel, Plasma Physics and Controlled Fusion Vol. 39, 223 (1997).

[3] P.T. Bonoli, R.R. Parker, M. Porkolab, J.J. Ramos, S.J. Wukitch, Y. Takase, S. Bernabei, J.C. Hosea, G. Schilling, J.R. Wilson, Nucl. Fus. 40 (2000) 1251.

[4] R. Walls, S. Bernabei and H. E. Evans: Fabrication of phased array microwave waveguide windows in Proc. IEEE Conf. On Plasma Science, Knoxville TN, Sept 1989

[5] P. Jacquet et al., Rev. Sci. Instrum. 68,(2), Feb 1997, p. 11776 


\section{External Distribution}

Plasma Research Laboratory, Australian National University, Australia

Professor I.R. J ones, Flinders University, Australia

Professor J oão Canalle, Instituto de Fisica DEQ/IF - UERJ , Brazil

Mr. Gerson O. Ludwig, Instituto Nacional de Pesquisas, Brazil

Dr. P.H. Sakanaka, Instituto Fisica, Brazil

The Librarian, Culham Laboratory, England

Library, R61, Rutherford Appleton Laboratory, England

Mrs. S.A. Hutchinson, JET Library, England

Professor M.N. Bussac, Ecole Polytechnique, France

Librarian, Max-Planck-Institut für Plasmaphysik, Germany

J olan Moldvai, Reports Library, MTA KFKI-ATKI, Hungary

Dr. P. Kaw, Institute for Plasma Research, India

Ms. P.J . Pathak, Librarian, Insitute for Plasma Research, India

Ms. Clelia De Palo, Associazione EURATOM-ENEA, I taly

Dr. G. Grosso, Instituto di Fisica del Plasma, Italy

Librarian, Naka Fusion Research Establishment, J AERI, J apan

Library, Plasma Physics Laboratory, Kyoto University, J apan

Research Information Center, National Institute for Fusion Science, J apan

Dr. O. Mitarai, Kyushu Tokai University, J apan

Library, Academia Sinica, Institute of Plasma Physics, People's Republic of China

Shih-Tung Tsai, Institute of Physics, Chinese Academy of Sciences, People's Republic of China

Dr. S. Mirnov, TRINITI, Troitsk, Russian Federation, Russia

Dr. V.S. Strelkov, Kurchatov Institute, Russian Federation, Russia

Professor Peter Lukac, Katedra Fyziky Plazmy MFF UK, Mlynska dolina F-2, Komenskeho Univerzita, SK-842 15 Bratislava, Slovakia

Dr. G.S. Lee, Korea Basic Science Institute, South Korea

Mr. Dennis Bruggink, Fusion Library, University of Wisconsin, USA

Institute for Plasma Research, University of Maryland, USA

Librarian, Fusion Energy Division, Oak Ridge National Laboratory, USA

Librarian, Institute of Fusion Studies, University of Texas, USA

Librarian, Magnetic Fusion Program, Lawrence Livermore National Laboratory, USA

Library, General Atomics, USA

Plasma Physics Group, Fusion Energy Research Program, University of California at San Diego, USA

Plasma Physics Library, Columbia University, USA

Alkesh Punjabi, Center for Fusion Research and Training, Hampton University, USA

Dr. W.M. Stacey, Fusion Research Center, Georgia Institute of Technology, USA

Dr. J ohn Willis, U.S. Department of Energy, Office of Fusion Energy Sciences, USA

Mr. Paul H. Wright, Indianapolis, Indiana, USA 
The Princeton Plasma Physics Laboratory is operated by Princeton University under contract with the U.S. Department of Energy.

\author{
Information Services \\ Princeton Plasma Physics Laboratory \\ P.O. Box 451 \\ Princeton, NJ 08543
}

Phone: 609-243-2750

Fax: 609-243-2751

e-mail: pppl_info@pppl.gov

Internet Address: http://www.pppl.gov 